\title{
Wie ich zur Drag Queen wurde*
}

\section{Eberhard Wolff}

Prof. Dr. rer. soc., Redaktor Kultur, Geschichte, Gesellschaft

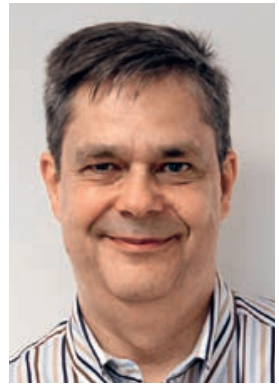

Unzählige Male haben wir diese Geschichte gehört: Auf dem Weg von Miami zupfte sich Haroldo Rodriguez Danhakl die Augenbrauen. Dann rasierte er sich die Beine. Nun war er zu einer «Sie» geworden. In New York kam sie schliesslich als Holly Woodlawn an.

Mit «Holly came from Miami F.L.A. ...» beginnt Lou Reeds Walk on the Wild Side von 1972. Damals lebten Menschen, die eine unkonventionelle Geschlechtsidentität besassen, versteckt, auf der «Wild Side» oder in der künstlerischen Avantgarde. In den Augen von «Normalen» waren solche Menschen bestenfalls verstörend - wie «Lola» für den «Kinks»-Sänger Ray Davies im gleichnamigen Lied von 1970. Rasierte Männerbeine kannte man allenfalls aus sogenannten Verwechslungskomödien - wie Manche mögen's heiss von 1959 mit Tony Curtis und Jack Lemmon.

Das deutsche Bundesverfassungsgericht hat letzten November von den Behörden gefordert, die Registrierung eines dritten Geschlechts zu ermöglichen oder ganz auf Geschlechtsangaben zu verzichten. Damit sollen die Persönlichkeitsrechte von intersexuellen Menschen gewahrt werden. Und die von Menschen, deren Geschlechtsidentität von ihrem biologisch definierten Geschlecht abweicht.

Der deutsche Geschlechter-Soziologe Stefan Hirschauer meinte dazu in einem erhellenden Zeitungsartikel [1], dass in modernen Gesellschaften ohnehin ein immer grösser werdender Raum zwischen und jenseits von eindeutigen Geschlechtszuordnungen entstehe. Auch die Kategorie «Staatsangehörigkeit» wird bei uns weniger eindeutig und wichtig, sagt Hirschauer.

«He» oder «She» sind keine so beinharten Alternativen mehr wie noch in der Zeile von Lou Reed. Die Grenzen zwischen den Geschlechtern werden durchlässiger. Wer im Gesundheitsbereich arbeitet, wird damit eher als andere konfrontiert. Solche grösseren kulturellen Veränderungen erscheinen aber nicht mit einem Schlag. Sie etablieren sich in kleinen Häppchen in unserem Alltag. Beim diesjährigen Fernsehhighlight Germany's Next Top Model brachte eine Gruppe «Drag Queens» den «Mädels» bei, wie man sich richtig in Szene setzt. Klar, die als Superfrauen umgestylten Männer sind «Paradiesvögel», total überzogen, mit allen Weiblichkeitsklischees, aber sie sind weniger "Outcasts» als früher. Sie werden auch bewundert, sind jetzt sogar Performancevorbilder für die jungen Models in spe bei Heidi Klum und ihrem multimedialen Millionenpublikum.
Die letzte «Zurich Pride»-Parade für sexuelle und geschlechtliche Vielfalt war ebenfalls keine so eindeutige Demonstration unterdrückter Minderheiten mehr. Seriös gesponsert von UBS, Credit Suisse und Post, mit den «Queer»-Abteilungen von SBB, VBZ und Stadtpolizei sowie mit den Parteien bis hin zur BDP ist sie auf dem besten Weg, zu einem Mehrheits-Event in Sachen Vielfalt zu werden. In zwanzig Jahren ist sie vielleicht das neue Sechseläuten.

Grössere kulturelle Veränderungen wie das Durchlässigwerden von Geschlechtergrenzen spiegeln sich aber auch im noch alltäglicheren Alltag. Männer gehen mit ihren Haaren immer häufiger auf eine Art um, die früher als exklusiv weiblich eingeschätzt worden wäre. Männer müssen heute nicht mehr heimlich in einer Frauenband spielen, um sich die Beine rasieren zu können. Für viele sportliche Velofahrer ist das eine Art Erkennungszeichen geworden. Sicher, das sei für eine bessere Windschlüpfrigkeit, Massage oder Wundheilung. Aber bereits wenn man die bessere Sichtbarkeit der Wadenmuskeln als Argument anführt, spielt die Ästhetik mit.

Der Männerzopf und der Männerdutt sind zur Selbstverständlichkeit geworden. Oder sind sie bereits ein Zeichen von neuer Männlichkeit, wie der Hipster-Bart? Eine Schweizer Klinik bietet die ästhetische Vermännlichung der Gesichtszüge an. Das wäre dann wiederum eine Akzentuierung der Geschlechtsunterschiede.

Vielleicht ist es auch eher der intensivere Umgang von Männern mit den eigenen Haaren (und dem ganzen Körper), der früher einfach als «weiblich» galt.

Männer dürfen nur nach Schweiss und Leder riechen, wurde einmal gesagt. Jetzt entfernen sich immer mehr Männer die Achselhaare, während sich bewegte Frauen bewusst wieder ihre Achselhaare wachsen lassen (und bunt färben).

Ich selber trage weder einen Male Bun, noch habe ich je meine Beine rasiert. Ich spiele weder in einer Frauenband, noch fahre ich ein Rennvelo. Und trotzdem haben die Veränderungen seit dem Walk on the Wild Side auch an mir ihre kleinen Alltagsspuren hinterlassen. Ich stutze seit ein paar Jahren im Sommer meine Achselhaare. Damit werde auch ich jedes Mal ein ganz kleines bisschen zu einer Holly. Einer ganz normalen, alltäglichen. Meiner herkömmlichen Geschlechtsidentität hat dies keinen Abbruch getan. 